$\xi=1$ 国

\title{
Fillers preparation for polymer composite and its properties - a review
}

\author{
T. Vinod Kumar ${ }^{1}$ *, M. Chandrasekaran ${ }^{2}$, P. Mohanraj ${ }^{3}$, Ravishankar Balasubramanian ${ }^{3}$, R. Muraliraja ${ }^{1}$, V. S. \\ Shaisundaram ${ }^{1,4}$ \\ ${ }^{1}$ Assistant Professor Department of Mechanical Engineering \\ ${ }^{2}$ Professor and Director Department of Mechanical Engineering \\ ${ }^{3}$ Student Department of Mechanical Engineering \\ ${ }^{4}$ Assistant Professor Department of Automobile Engineering Vels Institute of Science, Technology and Advanced Studies (VISTAS), \\ Chennai, Tamilnadu, India \\ *Corresponding author E-mail: vinodkmrmech@gmail.com
}

\begin{abstract}
This paper is a review about the manufacture of polymer matrix composite by the filler materials, property and its preparation. Day by day the role of composite materials in industrial and household applications is increased. By using the variety of matrix, reinforcement and filler materials the polymer composite obtains from it. To improve the mechanical properties of the polymer composite, important role is played by filler materials. There is a unique property for each type of filler materials, which is altered by changing the percentage of filler materials. Filler materials important purpose is to reduce the cost of material and it increase the mechanical properties, that also use to increase surface finish and thermal property. In this paper, the elaboration of polymer materials and its uses are discussed, which held later the synthesis of polymer composite by different fillers. The filler properties, manufacture methods, polymer composite properties are discussed.
\end{abstract}

\section{Keywords: Polymer Composite; Reinforcements; Fillers; Properties; Method; Procedures.}

\section{Introduction}

Two or more dissimilar polymer composite materials unite together to form a better and sole material. High-temperature creep, impact damage, chemical attack and water absorption are processed by PMC (Polymer Matrix Composite) which was decided by the property of the matrix. Thermosets or thermoplastics either derived from the resins of the matrix of PMC. $60 \%$ reinforce fiber is there in PMC in a volume form. Graphite, fiberglass and aramid are the fibers commonly found and used in Polymer Matrix Composite. Alternative synthetic fillers are generally utilized in PMC which also have a natural fibers / particles reinforcement in it. These fillers have low density, abundant availability, mechanical properties, and biodegradability. Different types of fibers like aircrafts, marine boats, and sporting equipment's such as golf shafts, tennis rackets, etc., all are reinforced with the application of Polymer Composites. The main objectives for the implementation of polymer composite in lot of applications are weight reduction, which have rather properties like non-conductive, noncorrosive, flexible, low maintenance, long life, and design flexibility.

1) By using the hand leaves, stem and foreign matter were removed which make it as a clean burr fraction and also as a fine particle by knife-type cutting mill [2].

2) By pressing the Sugarcane to take the extract of sugar Bagasse, the residue fiber remains [5].

The triggered new one material which are able to exist along with the environment like environmental regulations and social concerns. Biodegradable, renewable and recyclable and material re- source is the bio-fillers based on agriculture products [1]. To add with been along the environment few hazardous and few biodegradable materials like medical and dental applications are needed. All the bio-fillers has numerous benefits in renewed interest in low cost fillers, bulk supply, constant availability of resources, and the consumption of energy is low when it is compared with the fabricated/ synthesized fillers. From the view of researcher's these eco-friendly bio fillers in 21 st century it will get the potential to be the new material for the global environmental problem it be a partial solution. The Cotton harvesting is used to obtain the byproduct of ginning cotton burr. It is often used in boilers as fuels or as mulch. The material is not much expensive and availability is high. From the harvest cotton stripper, cotton burr was collected as a trash from the field [2]. Wood apple shell can used as an essential material as filler in biodegradable polymer composites, by its good mechanical strength and thermal stability it is good by comparing with other agricultural waste. Wood apple (Aegle marmelos) is in the order relates to the family Rutaceae. Wood apple can be easily seen in all the places in this world which is from the forest of Himalaya near the Southeast Asian countries. Coconut shell has good mechanical strength to be filler and thermal stability is strong by comparing with other agricultural waste. Coconut (cocosnucifera) is in the order relates to family Rutaceae commonly seen in Himalayan forest [1]. By the cross-linked nature of thermoset resins that unable to remold but it consists polymer matrix, glass fibers and variety of inorganic fillers. Still, by considering many of the thermoset based on GFRP (glass fiber reinforced plastics) waste continuously incinerated or land filled forwarded to undesirable effects to the environment and in addition it increased cost. When there is an increase in environmental matters 
as awareness and the subsequent need to protect the assets, redo process may transform a costly waste removal into a gainful one to use again as a material. For this it is used as a filler material [3]. To this add the pine apple flour filler in materials which is suggested as a good one to improve the properties of PLA (poly lactic acid) [4]. Bagasse is natural and comprised of fiber and essence, it is thick walled and generally long $(1.4 \mathrm{~mm})$. Bagasse is hugely part of lignocellu-losic squander which is found in tropical nations that utilization to create sugar stick, for example, Indian, Brazil, China, Cuba and Nigeria. The bagasse fiber (BF) packs are typically coarse and solid. In one route utilized as fuel for boilers alongside sugar processing plant or as a crude material for mash fabricating mash and paper items [5]. Nano clay used as fillers: Montmorillonite (MMT) minerals used as good nano clay fillers processing by keeping as dispensability in matrix, MMT contains nano sized layers of alumina sheets. It sandwiched among two silicate sheets which causes a net negative charge, that charge is counterbalanced by interchanged metal ions which is in the surface of the layers. MMT clays are naturally hydrophilic and it makes the organophilic to replace the exchangeable cation like alkyl amonium cations that renders them in the organic matrix to organophilic favoring intercalation/exfoliation [6]. Fillers increase the controlling strength up to the high at $10 \mathrm{wt} \%$. Some of the researchers analyzed that Nano improves the shear and tensile strength, fracture toughness and stiffness of the composite. Still the Nano filler chooses as an impinged into the polymer matrix which improves the Mechanical properties [7]. The sundi wood tidy (SWD) is framed by cutting of the sundi tree wood. The fundamental introductory natural constituents of sundi wood are glucomannan, cellulose, xylan and lignin. The sundi tree identifies with Micheliamontana tree species family and as often as possible accessible in Eastern piece of India [8]. Jatropha curcas, that's used in large level as drought resistant and perennial plant which relates to the Euphorbiaceae family. It has gained unique attention by its physicochemical properties which have oil seed and its benefit as a surface coating in industries and biodiesel feedstock. The Jatropha deoiled cake (JOC) is an important byproduct of oil extraction fro it that is considered to be a enormous cradle of bio energy, along with crude fiber and crude protein of about 14.3 $\mathrm{wt} \%$ and $46 \mathrm{wt} \%$, approximately for this purpose it used as a filler material [9]. Carbon nanotubes (CNTs) have an important role because it has a good structure and functional properties like the high mechanical strength, high aspect ratio and high electrical properties compare to others filler. CNT are generally mingled up of hexagonal structured graphene sheets formed as a tubular and crowned with half shape of fullerene structure. There are two types of CNT, (1) single walled nanotubes (SWNTs), the cylindrical structure was made using single graphene sheet. (2) Multi walled nanotubes (MWNTs), graphene layers are stacked to form numerous in cylinders along the interspacing of $0.34 \mathrm{~nm}[10]$. The industrial by-product fly ash (FA) used in power station which are fired using coal. Less quantity of about $30 \%$ only is used by cement industry, but the large quantity is dumped in landfill as millponds. Enormously it is a tough thing to find another sound environmental solution to dispose where it grows an interest by using it as a filler material to make extraordinary composites [11]. Plant fibers are usually consists of hemicelluloses, cellulose and lignin Cellulose that improves the mechanical properties of all the natural fiber. This is in order by micro-fibrils which enclose by two other main components like lignin and hemicelluloses. Cellulose micro fibrils easily find in an intertwined micro-fibrils in the cell wall, which is confirmed by the amorphous regions and nanocrystalline peaks. Only the acid hydrolysis able to separate both the things driving to crystalline domains by using the elastic modulus of $150 \mathrm{Gpa}$ [12]. The filler calcium carbonate has good physical properties, melting, glass transition, and crystallization behavior of 80 PHR polypropylene (PP) with different weights of linear low density polyethylene were studied [13]. Nylon filled Polycaprolactone (PCL) creates good improvement in stiffness with a continuously increase in ductility. Nylon fiber diameter is decreased by electrospining process it coated a good interfacial ad- hesion between filler and matrix [14]. To improve the mechanical properties, Spiky nanostructured nickels are used as fillers. [15]. the research which was going on for few decades few decades on dispersing of ceramic nanoparticles in to polymer matrix which is proved effective. It has enhanced ionic conductivity that challenges to form the network very efficiency. [16]. the thermal stability of the polymer matrix and mechanical strength are improved by the core-shell silica particles [17], [18].

This article gives an overview of the current and previous research work carried out in the topic of polymer composite materials with different type of fillers used. Firstly, the polymer composite fillers are reviewed and the methods to synthesis of particular fibers are discussed. The properties after incorporating these fibers are discussed and compared. Finally, the main challenges relating to synthesis of polymer composite with different category of fibers are discussed.

\section{Preparation of polymer composite with dif- ferent fillers}

The process of polymer composite with variety of fibres is analysed in this section in an order as it is discussed in introduction. The coconut shells were used in introduction is at first wash away with water that eliminates the scums and it dries the shells in the furnace at $110^{\circ} \mathrm{C}$ for 24 hours. Those shells dried first thing is to crush by using the crusher. The crushed shells were converted by ball milling process the crushed shells become powder fine particles and followed a sieve shaker for element exploration. Cotton burr formed from the harvest of cotton stripper that was collected as part from the field trash. By using the hand leaves, foreign matters and stem are removed, to powder it by knife type cutting mill and by the knife type cutting mill and by the size two fractions were produced as $1-\mathrm{mm}, 2-\mathrm{mm}$.Polymer blended were formulated with $10,20,30$ or $40 \%$ of the by-product filler. One by one all the mixture of materials was usually blended and safely kept in covered double zip-locked bags for 1 day before the extrusion. Cotton seed hulls produced from acid-delinting cotton seed. All the seeds are stated to crack with an 8Bauer disc mill, and by the air classification the hulls are separated likewise it separated into two fraction size of 1-mm, 2-mm and it is manually blended with polymer and for 1 day it safely covered in a double zip-locked bags, before the extrusion. Extrusion started in a single screw extruder by the help of four temperature zone. For FRP (fiber reinforcement plastic) thermostable materials three main recycling methods are used, the first is incineration, with moderate energy to recover by the heat produced during carbon-based portion ignition secondly the thermal or chemical recycling, like solvolysis, pyrolysis which is equal to thermal decomposition processes, along the partial recovering of reinforcing fibers and thirdly the mechanical recycling, that involves by breaking-down the composite by milling, shredding, commination or other equal mechanical processes, that reduce the size to fibrous or powdered products could be incorporated in one way as reinforcement or in other ways as filler into new composite materials. Process with size reduction to powdered products so it can be used as a filler material. Pineapple flour Kept in oven to dry at $105^{\circ} \mathrm{C}$ for $24 \mathrm{~h}$ which is adjusted the moisture content to1-3\%, and it store in a sealed polyethylene bags prior to compound. The PLA starts to blend with the pine apple flour. The remaining not crushed bagasse. To produce clay filled composites, preheated Nano clay and microclay of definite weight fraction that added one by one in the epoxy resin. By using magnetic stirrer the clay was mixed vigorously in epoxy at $70^{\circ} \mathrm{C}$ for $2 \mathrm{~h}$ and the homogeneous mixture was cooled to room temperature followed by the addition of hardener. Immediately the fiber and epoxy extent is kept up at $60: 40$ by weight. The Nano powder start to dry at $100^{\circ} \mathrm{C}$ for $1 \mathrm{~h}$ preced-ing mixing with epoxy matrix. $3 \mathrm{wt} \%$ of epoxy of Nano filler start to mix with epoxy in a temperature took after by alluring stirrer and ultrasonic shower for $60 \mathrm{~min}$. The made overlays and gently cured at $60^{\circ} \mathrm{C}$ at various shape weight $(10,17,24$ and $31 \mathrm{~kg} / \mathrm{cm} 2$ ) for $20 \mathrm{~min}$. Furtherly it cured at room temperature 
for minimum 5 days. The sundi wood dust (SWD) particles taken by the side of North eastern piece of India that have normal molecule estimate $2 \mu \mathrm{m}$ and thickness $0.779 \mathrm{gm} / \mathrm{cc}$ by cleaning and drying sundi wood dust this is utilized as a filler epoxy pitch in the readiness of the composites. The Jatropha seeds are together hulled, blended, and chemically deoiled to use as n-hexane at $558^{\circ} \mathrm{C}$ for $6 \mathrm{~h}$. The JOC starts to dry dried in a Heraeus oven at $608^{\circ} \mathrm{C}$ for $24 \mathrm{~h}$ which refine and sieves in $300 \mathrm{~lm}$. The result of it as a start to dry powder at $808^{\circ} \mathrm{C}$ in a vacuum oven for $24 \mathrm{~h}$ to eliminate the moisture and later on stored in a desiccator prior to compounding. The carbon nanotubes are created under various techniques like laser removal, bend vanishing strategy, electrolysis, compound vapor affidavit, fire blend and so forth every year. The techniques broadly used in CNTs are arc evaporation method, laser ablation and chemical vapour deposition for synthesis. The Fly Ash (9A) particles start to immerse in 0.5 wt.\% aqua solution of surfactant sodium lauryl sulphate (SLS) at $50^{\circ} \mathrm{C}$ under long time stirring. After $10 \mathrm{~h}$, the solve particles slowly filtered and one by one washed from distilled water many times by removing nonadsorbed SLS next step is to dry under vacuum for 2 days at $50^{\circ} \mathrm{C}$ and add it to polymer matrix. The Cellulose generation of cotton filaments begin to dewax by bubbling in $2 / 1$ ethanol- toluene alcohol to alcohol proportion for $2 \mathrm{~h}$. Holocellulose (cellulose + hemicelluloses) shaped from dewaxed cotton filaments when it bubbles under $0.7 \mathrm{wt} \%$ sodium chlorite arrangement at $\mathrm{pH} 4$ for 2 $\mathrm{h}$ utilizing a 1:50 fiber to alcohol proportion. Slowly it treated with sodium bi-sulphate solution, taken back by the filter, washing and drying at $100^{\circ} \mathrm{C}$ until equal weight formed which is able to use as filler in polymer matrix. Calcium Carbonate is the materials to dry properly. The materials starts to dry in circulating air oven at $80^{\circ} \mathrm{C}$ for a period of $3 \mathrm{~h}$ just before the process. $80 \mathrm{phr}$ PP (polypropylene) will melt and blend with (low density polyethylene)LLDPE at 10, 20wt \% CaCo3, 30, 40, and $50 \mathrm{phr}$ LLDPE it uses double screw extruder with a special mixing head. It cold the above blend. The nylon fibres used to prepare the composites that made up impregnation of the electro spun fibers mat along a molten (polycaprolactone) PCL, with compression moulding approach The Nano fiber tangle begin to sandwich between PCL films. By the use of warmth and weight in a press at $90^{\circ} \mathrm{C}, \mathrm{PCL}$ begin to dissolve and it permeated between the voids in the tangle, constituting a continuous stage in which fiber were scattered. The Spiky Nanostructured Nickel composite examples were set up by scattering in Polydimethylsiloxane (PDMS) copolymer as a 500 sections in weight of nickel particles per hundred pitch (phr). With a specific end goal to maintain a strategic distance from the mix delicately blended the obliteration of the Nano metric sharp tips on the particles surface that outcomes in a decrease of the piezo resistive reaction. By including the curing operator next blend, the came about glue it was out-gassed for $1 \mathrm{~h}$ under vacuum at room temperature, that dodges the arrangement of air pockets. Finally, the composite blend begin to poured in polymethyl methacrylate to shape and thermally cure in a broiler at $75^{\circ} \mathrm{C}$ for $10 \mathrm{~h}$. The CERAMIC NANOWIRE (LLTO) prepared to get ready by electro turning of polyvinylpyrrolidone polymer fiber that contains the applicable salts to calcine it in the temperature scope of 600-900 ${ }^{\circ} \mathrm{C}$ in air for $2 \mathrm{hr}$. The Core-Shell Silica has $0.2 \mathrm{~g}$ of vinyl $\mathrm{Si}$ to crush and scatter in $10 \mathrm{~mL}$ of refined THF took after by ultrasonication for $30 \mathrm{~min}$. $0.8 \mathrm{~g}$ of PEGMA and $0.04 \mathrm{~g}$ of AIBN begin to disintegrate in $5 \mathrm{~mL}$ of refined THF and it exchange to the silica scattered arrangement. The aftereffect of the arrangement was transferred to a $50 \mathrm{ml}$ Schlenk carafe that outfitted with an attractive blend ring bar and a condenser. The three back to back stop pump-degassed the arrangement by defrost cycles to expel oxygen and it dispersed under sonication for $30 \mathrm{~min}$ only in far the polymerization, and after that it was gradually warmed to $70^{\circ} \mathrm{C}$ for $24 \mathrm{~h}$ under environment which changes over the monomer. The monomers not reacts to free polymers that unattached to the silica surface to remove by washing with THF and resultant core-shell silica particle slowly collect under centrifuge process.ZIF-7:150mL DMDF start to add to a solid mixture of $0.453 \mathrm{~g}$ $\mathrm{Zn}$ ( 6 and1.154g stirr for $23 \mathrm{~h}$ at room temperature. Separate the product centrifugally to wash it three times with methanol. Last time it dispersed in methanol solution to keep it under stirring for one more day after that separate it to allow and form a complete solvent exchange still DMF is very hard to remove. Without heating the solvent to remove it the particles are directly dispersed in to the $\mathrm{H} 2 \mathrm{O} / \mathrm{EtOH}(30 / 70)$ mixture. By doing this the particle agglomeration start to occur as dry in a process to avoid it. The few bit of the last arrangement is dried independently to gauge the mass of ZIF-7 [19]. Several ZIFs can be synthesized easily as fast as in low cost.Many studies had investigated ZIFs, like ZIF-8 [20,21], ZIF-7, fillers with different polymers, that includes polysulfone [22], Matrimid [23], ZIF-90 [24], PBI [25] and polyimide

\section{Result and discussion}

COTTON BURR IN POLY (LATIC ACID) (PLA) without filler had a TS of $58 \pm 2 \mathrm{~N} / \mathrm{mm}^{2}$, E of $13 \pm 1 \%$, and a YM of $609 \pm 49 \mathrm{MPa}$. Generally, by adding the filler materials it reduces the mechanical properties of PLA. That reduces all the TS, E, and YM. The bigger estimated particles begin to use in composites of PLA that outcome in materials with a similar TS and E however somewhat more prominent YM. By adding the cotton blur to PLA it reduces the properties to use it as in selected application to reduce the cost which is important and the mechanical properties reduced to accept it. COTTON BURR IN LOW DENSITY POLYETHYLENE (LDPE) had YM of $46 \pm 7 \mathrm{MPa}, \mathrm{E} \quad 693 \pm 203 \%$, and TS of $9 \pm 1 \mathrm{~N} / \mathrm{mm}^{2}$. The Composite materials comes about by including the fillers that unobtrusively lessened TS (aside from the 10\% Addition of cottonseed frames, which had a similar TS). The amount of filler increases by the reduction of TS. By addition the minute amount of burr it results in the reduction of Elongation. By adding the burr filler materials to LDPE it increases the composite material's YM. So that it needs a stiffer Polyethylene in a low cost [26]. Wood apple bio fillers density, also the void content of the wood apple shell particulates composites become less along with filler content increasement in to polymer. Finally it noted as the increase in filler content, shows the increase in tensile strength. The maximum strength of tensile produced as the $15 \mathrm{wt} \%$ to reinforce composite in wood apple shell. The maximum tensile strength formed from wood apple shell is $43.6 \mathrm{Mpa}$. The flexural quality demonstrates a relentless increment when the filler stacking expands still gradually it diminish in quality of flexural from 15 to $20 \mathrm{wt} \%$ filler stacked bio-composite, this occurs because of split development, increment in void substance and poor fillerframework grip quality in the lattice composite. The most extreme flexural quality shaped as $78.19 \mathrm{MPa}$ for wood apple shell. At the broaden the erosion rate is discovered which happens at 45 to 60 impingement plots for all the composite examples in various test conditions not reacts of filler stacking, that affirms the material, which acts as a semi flexible. Coconut shell bio-fillers begins to high in filler content, which comes about increment in elasticity. The most extreme quality got of tractable for $15 \mathrm{wt} \%$ is acquired coconut shell is $41.3 \mathrm{MPa}$ and the flexural quality increments persistently as the filler stacking expands still there is little reduction in flexural quality from 15 to $20 \mathrm{wt} \%$ filler stacked bio composite. The maxi-mum flexural quality is acquired for coconut shell is $68.25 \mathrm{Mpa}$ [27-29].Thermoset waste fillers have the fractional substitution of sand totals by GFRP squander materials that have a general incremental impact on both flexural and compressive qualities in polymer mortar (PM). PMs altered with coarse waste (CW) enhance the mechanical conduct over fine waste (FW) one may in flexural or in pressure. The joining of the silane coupling operator signifies to enhance the mechanical conduct of polymer mortar (PM). The right blend of factor's levels the amplify of the two flexural and compressive qualities of the changed polymer mortar that accomplish for $8 \%(\mathrm{w} / \mathrm{w})$ of sand traded by coarse GFRP squander recyclates and consolidation of $1 \%$ of dynamic silane to gum fastener [30]. Pine apple flour as filler that have elasticity low on with an expansion in flour stacking, from 58.8MPa for unadulterated PLA (POLY LACTIC ACID) to $26.9 \mathrm{MPa}$ for $40 \%$ pine- 
apple flour stacking. The flexural quality turn out to be low by including the flour, from 109.1MPa for unadulterated PLA to 65.9MPa for the $40 \%$ heap of pineapple flour. The capacity modulus of the PLA bio composites along the flour is high than the flawless PLA. The firmness of the PLA bio-composite exceptionally increments after $30 \%$ of pine apple flour added to PLA that enables the viable worry to exchange from PLA network to the flour. The expansion of pine apple flour to the bio-composite end up beneficial outcome on the HDT(heat redirection temperature). The HDT of WF filled PLA bio-composites was higher than the HDT of the PLA sap [31-33]. The malleable modulus expanded with a comparing addition in the bagasse particles. The rigidity expanded from $8.10 \mathrm{Mpa}$ for the reused low thickness polyethylene (RLDPE) lattice to a greatest of $9.20 \mathrm{Mpa}$ and $11.34 \mathrm{Mpa}$ at $20 \mathrm{wt} \%$ UBP and $30 \mathrm{wt} \%$ CBP. It is watched that with increment in wt $\%$ bagasse particles in the polymer grid will build the hardness estimations of the composite. The greatest composites have a twist in the qualities at $20 \mathrm{wt} \%$ UBP and $30 \mathrm{wt} \%$ CBP. There is a reduction in the effect quality and break sturdiness by the expansion of bagasse molecule. The concentration of bagasse particles increase to reduce the capable of matrix that absorbs the energy and it reduces the toughness. The grades of composites recommend to use the production of less strength car bumpers and some structural applications [34].The fillers Nano clay of the water content continuously decreases when the nanoclay content increases and maximum become low to note it for $5 \mathrm{wt} \%$ Nano clay filled composites. The demonstrated $5 \mathrm{wt} \%$ micro clay filled composite reduces the water mass uptake, that decreases is less to Nano clay filled composites. The stress-strain patterns has been changed due to adding the Nano clay or Micro clay in the composites. The Nano mud content increments alongside the modulus however the quality and strain esteems starts to lessen over $3 \mathrm{wt} \%$ of mud implantation. The nanoclay framed by including the composites which changes the disappointment designs from fragile to pliable disappointment. The nanoclay assumes the part of split arrestor while it stacks by inciting disfigurement instruments like the break sticking and debonding that outcomes in the example it flops under twisted condition. The Tg (Glass transition temperature) of the composites continuously become high as the nanoclay content increases [6].

The flexural quality framed and modulus of GF-Nano composite enhances for 14 and $24 \%$. High particular surface territory needed bignanoAl2O3 in polymer surface. The enormous interface part re-duces stretch focus at the interface and it creates the heap exchange productivity from the epoxy lattice to the hard nanoAl2O3 successfully. At keeps going a change in flexural quality details to ascribe to the better load exchange. Extra the 3 wt. \% of Nano $\mathrm{A} 12 \mathrm{O} 3$ into epoxy lattice composite there is no effect on glass change temperature. The ILSS esteems gets low alongside inwrinkle in Nano filler Al2O3 [35].

Sunni wood tidy framed by height of filler weight $\%$, the maximum load, malleable pressure, elastic modulus and strain esteem expands that go to the greatest at $10 \%$ filler content by wt. furthermore, the properties turns out to be low and the base at $15 \%$ filler wt. The ductile anxieties esteems most extreme and least along speed of $1 \mathrm{~mm} / \mathrm{min}$ are $28.29 \mathrm{MPa}$ and $10.83 \mathrm{MPa}$ at $10 \%$ and $15 \%$ filler wt. The strain estimations of most extreme and least are 19.10 and 2.69 separately at $10 \%$ and $15 \%$ filler wt.

At the point when the filler wt $\%$ builds the flexural stretch, flexural modulus and strain esteem turn out to be high and furthermore most extreme at $10 \%$ filler wt. The properties begin diminishing and move toward becoming limit at $15 \%$ filler wt. The value of flexural stress is of maximum and minimum $47.65 \mathrm{MPa}$ and $18.2 \mathrm{MPa}$ is $10 \%$ and $15 \%$ filler. The value of flexural modulus are maximum and minimum is $1335.20 \mathrm{MPa}$ and $435.70 \mathrm{MPa}$ is $10 \%$ and $0 \%$ filler wt. $\%$ [36]. The (elasticity) TS noted to diminish constantly with in-wrinkling (Jatropha deoiled cake) JOC content in the polymer framework. The unadulterated (medium-thickness Polyethylen)MDPE have (rigidity) TS of roughly $16.7 \mathrm{MPa}$, it includes the $10 \%$ JOC expanded TS to $18 \mathrm{MPa}$, the TS diminished to $15.9 \mathrm{MPa}$ when the proportion of JOC in the lattice expanded to
$20 \%$, and the TS dropped to $8.9 \mathrm{MPa}$ at $50 \mathrm{wt} \%$ JOC stacking. The Tensile modulus (E) expanded to a specific degree with cake expansion and began to diminish with expanding JOC proportion in the composites. By including 10\% JOC expanded tensile modulus by $63 \%$ over the perfect MDPE, yet tensile modulus esteems somewhat dropped with additionally increments in JOC content. Increment in flexural quality (FS) was seen at $10 \%$ filler stacking. The flexural quality diminished with the expansion in the filler stack substance of the cake. The consideration of $50 \mathrm{wt} \%$ JOC diminished FS to $13 \%$ over the slick network. Flexural modulus (FM) expanded with expanding JOC content. Composites with 50 wt $\%$ JOC stacking showed the best FM with $29 \%$ expansion over the perfect MDPE. The effect quality turns out to be low around $68 \%$ and $71 \%$ for the composites that heaps with $10 \mathrm{wt} \%$ and 50 wt $\%$ cake, when it contrast and flawless network [9]. Carbon Nano tubes (CNTs) with a phenomenal mechanical properties called high Youthful's modulus, high angle proportion, low thickness, high elasticity. Increment in hardness up to a factor of 3.5 by stacking 2 wt. \% of (single walled Nano tube) SWNT into epoxy frame work. The critical CNT content in matrix mechanical properties becomes low with increasing critical loading of CNTs. Formation of composite contains 1 wt. \% CNT to show $4.5 \%$ increase in tensile strength than in neat polycarbonate. Increase of (multi walled carbon Nano tube) MWNTs signifies with decrease in tensile strength or elongation at break. There is a continuity of the Young's modulus at a $7 \mathrm{wt}$. \% that loads to SWNTs. The mix of CNTs and polymer framework means to another appealing electrical properties to lead the polymers. Every one of the polymers begin to use for various designing applications, for example, film, antistatic covering and movies, electrical leading cements, electromagnetic obstruction protecting materials for electronic gadgets warm interface materials and so on. [10]. The surfactant-actuated FA particles upgrade the elasticity of the composite almost $33 \%$ and $75 \%$ expanded to the composite that can't alter FA and slick PVA (poly vinyl alchol) [37]. Crystallinity index (Ic) of cellulose in polymer matrix is $57 \%$. For the less filler content ( $5 \mathrm{wt} . \%$ ), the warm security of the framework can't connote the influenced one as the nearness of the fillers, that demonstrates a low level top around $415{ }^{\circ} \mathrm{C}$ for all saw materials. The $15 \mathrm{wt} . \%$ cellulose has a decrease in thermal degradation. Polycarpolactone (PCL) has young's modulus of $330 \mathrm{Mpa}$ and it is increase to $426 \mathrm{Mpa}$ for $5 \%$ of filler and further increases to $497 \mathrm{Mpa}$ for $15 \%$ of cellulose (CE). Like the same there is a slight increase in tensile strength and a big decrease in elongation because of increase in cellouse (CE) [38]. Which is viewed as a change in the elasticity, the flexural modulus, and scored Izod affect quality on account of PP/LLDPE filled to 20 wt $\%$ of $\mathrm{CaCO} 3$ [39]. Polycaprolactone (PCL) not have any filler but have young modulus of 352Mpa to addition of $3 \%$ of filler in PCL to show good improvement in young modulus from 530Mpa but young modulus starts to decrease with an increase in filler material and also stress at yield to show this same phenomenon. By utilizing the less filler substance (3\%), it is shaped that the got composites displayed by the firmness and quality, as well as expanded pliability [40]. In fiber estimate the spiky Nano organized nickel the main a few parameters influences the whole mechanical qualities of a composite framework. The filler write, shape and sum, alongside the effective coupling of fillers and polymer lattice, entirely pull in the mechanical properties of the composites. Physical amounts like compressive or flexural quality, hardness and Young's modulus begins to enhance as the filler content increments. Tensile modulus of PDMS is $1.64 \mathrm{mpa}$ to $8.34 \mathrm{Mpaand}$ also compressive modulus increases from $1.48 \mathrm{Mpa}$ to $6.18 \mathrm{Mpa}$ for $10 \%$ of nickel filler and dynamic modulus increases from $2.99 \mathrm{Mpa}$ to $28.98 \mathrm{Mpa}$ [15]. Effectively the ionic conductivity increases by the ceramic fillers dispersing ceramic particles in polymer matrix during that time there is an improvement in mechanical strength and electrochemical stability. By including the earthenware molecule fillers necessarily impede the polymer crystallization or to subsidize remarkably conductive border layers amongst polymer [16]. Core shell silica enhances lithium transference number, ionic conductivity, 
mechanical steadiness, and cycle performance. As a result it got has the assimilation of core shell silica fillers increases both the tensile and young's modulus. The decrease in the percentage of elongation at break when the filler contents increases [41]. The presence becomes low when the ZIF-7 filler start to increase permeability same time it reduce with growing ZIF-7 fillers. The ZIF 7 blended lattice layers gives a decent execution for $\mathrm{CO}_{2}$ detachment from liquid methane and different gas streams. At the high heaping of the ZIF-7 fillers, the discrimination is additionally expanded however the porousness is lessened.

\section{Conclusion}

Earlier researchers have prepared the polymer composite with different type of fillers and tests were carried out such as YS, Impact strength of the material, tension strength, flexural strength etc., are reported in the research papers are reviewed in this review. Mechanical, Dynamic and thermal analysis of Areca nut filler with carbon Nano powder in polymer composite is relatively scarce.

\section{References}

[1] Ojha, S., Raghavendra, G., \& Acharya, S. K. (2014). A comparative investigation of bio waste filler (wood apple-coconut) reinforced polymer composites. Polymer Composites, 35(1), 180-185.

[2] Sutivisedsak, N., Cheng, H. N., Dowd, M. K., Selling, G. W., \& Biswas, A. (2012). Evaluation of cotton by products as fillers for poly (lactic acid) and low density polyethylene. Industrial crops and products, 36(1), 127-134.

[3] Ribeiro, M. C. S., Meira-Castro, A. C., Silva, F. G., Santos, J., Meixedo, J. P., Fiúza, A.,\&Alvim, M. R. (2015). Re-use assessment of thermoset composite wastes as aggregate and filler replacement for concrete-polymer composite materials: A case study regarding GFRP pultrusion wastes. Resources, Conservation and Recycling, 104, 417-426.

[4] Kim, K. W., Lee, B. H., Kim, H. J., Sriroth, K., \& Dorgan, J. R. (2012). Thermal and mechanical properties of cassava and pineapple flours-filled PLA bio-composites. Journal of thermal analysis and calorimetry, 108(3), 1131-1139.

[5] Agunsoye, J. O., \& Aigbodion, V. S. (2013). Bagasse filled recycled polyethylene bio-composites: Morphological and mechanical properties study. Results in Physics, 3, 187-194.

[6] Mohan, T. P., \& Kanny, K. (2011). Water barrier properties of nanoclay filled sisal fibre reinforced epoxy composites. Composites Part A: Applied Science and Manufacturing, 42(4), 385-393.

[7] Nayak, R. K., Rathore, D., Routara, B. C., \& Ray, B. C. (2016). Effect of nano fillers and cross head velocity on interlaminar shear strength of glass fiber reinforced polymer composite. International Journal of Plastics Technology, 20(2), 334-344.

[8] Kumar, R., Kumar, K., Sahoo, P., \& Bhowmik, S. (2014). Study of mechanical properties of wood dust reinforced epoxy composite. Procedia Materials Science, 6, 551-556.

[9] Elshaarani, M. T., Yaakob, Z., Dahlan, K. Z. M., \& Mohammad, M. (2013). Jatropha deoiled cake filler-reinforced medium-density polyethylene biocomposites: Effect of filler loading and coupling agent on the mechanical, dynamic mechanical and morphological properties. Polymer Composites, 34(5), 746-756.

[10] Mittal, G., Dhand, V., Rhee, K. Y., Park, S. J., \& Lee, W. R. (2015). A review on carbon nanotubes and graphene as fillers in reinforced polymer nanocomposites. Journal of Industrial and Engineering Chemistry, 21, 11-25.

[11] Nath, D. C. D., Bandyopadhyay, S., Gupta, S., Yu, A., Blackburn, D., \& White, C. (2010). Surface-coated fly ash used as filler in biodegradable poly (vinyl alcohol) composite films: Part 1-the modification process. Applied Surface Science, 256(9), 2759-2763.

[12] Ludueña, L., Vázquez, A., \& Alvarez, V. (2012). Effect of lignocellulosic filler type and content on the behavior of polycaprolactone based eco-composites for packaging applications. Carbohydrate polymers, 87(1), 411-421.

[13] Ghalia, M. A., Hassan, A., \& Yussuf, A. (2011). Mechanical and thermal properties of calcium carbonate-filled PP/LLDPE composite. Journal of Applied Polymer Science, 121(4), 2413-2421.

[14] Neppalli, R., Marega, C., Marigo, A., Bajgai, M. P., Kim, H. Y., \& Causin, V. (2010). Poly ( $\varepsilon$-caprolactone) filled with electrospun nylon fibres: a model for a facile composite fabrication. European polymer journal, 46(5), 968-976.
[15] Stassi, S., \& Canavese, G. (2012). Spiky nanostructured metal particles as filler of polymeric composites showing tunable electrical conductivity. Journal of Polymer Science Part B: Polymer Physics, 50(14), 984-992.

[16] Liu, W., Liu, N., Sun, J., Hsu, P. C., Li, Y., Lee, H. W., \& Cui, Y. (2015). Ionic conductivity enhancement of polymer electrolytes with ceramic nanowire fillers. Nano letters, 15(4), 2740-2745.

[17] Shim, J., Kim, D. G., Kim, H. J., Lee, J. H., \& Lee, J. C. (2015). Polymer Composite Electrolytes Having Core-Shell Silica Fillers with Anion-Trapping Boron Moiety in the Shell Layer for AllSolid-State Lithium-Ion Batteries. ACS applied materials \& interfaces, 7(14), 7690-7701.

[18] Tanimoto, M., Yamagata, T., Miyata, K., \& Ando, S. (2013). Anisotropic thermal diffusivity of hexagonal boron nitride-filled polyimide films: effects of filler particle size, aggregation, orientation, and polymer chain rigidity. ACS applied materials \& interfaces, 5(10), 4374-4382.

[19] Li, T., Pan, Y., Peinemann, K. V., \& Lai, Z. (2013). Carbon dioxide selective mixed matrix composite membrane containing ZIF-7 nano-fillers. Journal of membrane science, 425, 235-242.

[20] Zhang, C., Dai, Y., Johnson, J. R., Karvan, O., \&Koros, W. J. (2012). High performance ZIF-8/6FDA-DAM mixed matrix membrane for propylene/propane separations. Journal of Membrane Science, 389, 34-42.

[21] Liu, X. L., Li, Y. S., Zhu, G. Q., Ban, Y. J., Xu, L. Y., \& Yang, W. S. (2011). An Organophilic Pervaporation Membrane Derived from Metal-Organic Framework Nanoparticles for Efficient Recovery of Bio-Alcohols. Angewandte Chemie International Edition, 50(45), 10636-10639.

[22] Zornoza, B., Seoane, B., Zamaro, J. M., Téllez, C., \& Coronas, J. (2011). Combination of MOFs and Zeolites for Mixed-Matrix Membranes. ChemPhysChem, 12(15), 2781-2785.

[23] Ordonez, M. J. C., Balkus, K. J., Ferraris, J. P., \&Musselman, I. H. (2010). Molecular sieving realized with ZIF-8/Matrimid ${ }^{\circ}$ mixedmatrix membranes. Journal of Membrane Science, 361(1), 28-37.

[24] Bae, T. H., Lee, J. S., Qiu, W., Koros, W. J., Jones, C. W., \& Nair, S. (2010). A High-Performance Gas-Separation Membrane Containing Submicrometer-Sized Metal-Organic Framework Crystals. Angewandte Chemie International Edition, 49(51), 9863-9866.

[25] Yang, T., Xiao, Y., \& Chung, T. S. (2011). Poly-/metalbenzimidazolenano-composite membranes for hydrogen purification. Energy \& Environmental Science, 4(10), 4171-4180.

[26] Tserki, V., Matzinos, P., \& Panayiotou, C. (2003). Effect of compatibilization on the performance of biodegradable composites using cotton fiber waste as filler. Journal of applied polymer science, 88(7), 1825-1835.

[27] Toro, P., Quijada, R., Yazdani-Pedram, M., \& Arias, J. L. (2007). Eggshell, a new bio-filler for polypropylene composites. Materials Letters, 61(22), 4347-4350.

[28] Li, H. Y., Tan, Y. Q., Zhang, L., Zhang, Y. X., Song, Y. H., Ye, Y., \& Xia, M. S. (2012). Bio-filler from waste shellfish shell: preparation, characterization, and its effect on the mechanical properties on polypropylene composites. Journal of hazardous materials, 217, 256-262.

[29] Yao, Z., Xia, M., Ge, L., Chen, T., Li, H., Ye, Y., \& Zheng, H. (2014). Mechanical and thermal properties of polypropylene (PP) composites filled with $\mathrm{CaCO} 3$ and shell waste derived bio-fillers. Fibers and Polymers, 15(6), 1278-1287.

[30] Zheng, Y., Shen, Z., Cai, C., Ma, S., \& Xing, Y. (2009). The reuse of nonmetals recycled from waste printed circuit boards as reinforcing fillers in the polypropylene composites. Journal of Hazardous Materials, 163(2), 600-606

[31] Kim, H. S., Yang, H. S., Kim, H. J., Lee, B. J., \& Hwang, T. S. (2005). Thermal properties of agro-flour-filled biodegradable polymer bio-composites. Journal of Thermal Analysis and Calorimetry, 81(2), 299-306.

[32] Zaini, M. J., Fuad, M. A., Ismail, Z., Mansor, M. S., \&Mustafah, J. (1996). The effect of filler content and size on the mechanical properties of polypropylene/oil palm wood flour composites. Polymer International, 40(1), 51-55.

[33] Yang, H. S., Kim, H. J., Son, J., Park, H. J., Lee, B. J., \& Hwang, T. S. (2004). Rice-husk flour filled polypropylene composites; mechanical and morphological study. Composite Structures, 63(3), 305-312

[34] Sanadi, A. R., Caulfield, D. F., Jacobson, R. E., \& Rowell, R. M. (1995). Renewable agricultural fibers as reinforcing fillers in plastics: Mechanical properties of kenaffiber-polypropylene composites. Industrial \& Engineering Chemistry Research, 34(5), 1889-1896.

[35] Luyt, A. S., Molefi, J. A., \& Krump, H. (2006). Thermal, mechanical and electrical properties of copper powder filled low-density 
and linear low-density polyethylene composites. Polymer Degradation and Stability, 91(7), 1629-1636.

[36] Kranthi, G., \& Satapathy, A. (2010). Evaluation and prediction of wear response of pine wood dust filled epoxy composites using neural computation. Computational Materials Science, 49(3), 609614.

[37] Ismail, H., \& Shaari, S. M. (2010). Curing characteristics, tensile properties and morphology of palm ash/halloysite nano tubes/ethylene-propylene-diene monomer (EPDM) hybrid composites. Polymer Testing, 29(7), 872-878.

[38] Tang, C., \& Liu, H. (2008). Cellulose nanofiber reinforced poly (vinyl alcohol) composite film with high visible light transmittance. Composites Part A: Applied Science and Manufacturing, 39(10), 1638-1643.

[39] Skrtic, D., Antonucci, J. M., \& Eanes, E. D. (1996). Improved properties of amorphous calcium phosphate fillers in remineralizing resin composites. Dental Materials, 12(5-6), 295-301.

[40] Buggy, M., Bradley, G., \& Sullivan, A. (2005). Polymer-filler interactions in kaolin/nylon 6, 6 composites containing a silane coupling agent. Composites Part A: Applied Science and Manufacturing, 36(4), 437-442.

[41] Zhou, Y., Wang, L., Zhang, H., Bai, Y., Niu, Y., \& Wang, H. (2012). Enhanced high thermal conductivity and low permittivity of polyimide based composites by core-shell Ag@ SiO2 nanoparticle fillers. Applied Physics Letters, 101(1), 012903. 